\title{
Synthesis and fabrication of porous calcium phosphate ceramics for antibacterial bone substitutes
}

\author{
J.C. Hornez, F. Bouchart, E. Meurice, M. Descamps and A. Leriche \\ Laboratoire des Matériaux Céramiques et Procédés Associés - Université de Valenciennes et du Hainaut- \\ Cambrésis, ZI du Champ de l'Abbesse, 59600 Maubeuge, France
}

\begin{abstract}
Calcium phosphate ceramics like hydroxyapatite (HA) are widely used to repair and reconstruct damaged parts of the human skeleton. This material is currently available as injectable cements, granules or macroporous blocks. The most familiar materials are granule shaped ones because their conveniency to be implanted in human body. In this study, a new manufacturing procedure to fabricate dense, microporous and macroporous hydroxyapatite spherical granules based on a lost wax principle and allowing the fabrication of beads with a fully controlled porosity is presented. The HA granules porous structure is used to impregnation by gentamicine and other active substances. The drug and phage releasing kinetics are compared as a function of time and ceramic porosity.
\end{abstract}

\section{INTRODUCTION}

Bioceramic materials as calcium phosphate ceramics and in particular hydroxyapatite (HA) and tricalcium phosphate $\beta$ ( $\beta$-TCP) because of their excellent biocompatibility, bioactivity and osteoconduction properties are widely used to repair and reconstruct damaged parts of the human skeleton and especially as bone substitutes in the filling of bone defects [1]. These materials are available in the form of injectable cements, granules or macroporous blocks. Calcium phosphate granules have been generally selected for classical bone filling [2]. However, these granules present irregular shapes and do not allow for optimal filling of bone cavity or defect. To overcome this problem, adjunction of a binding agent such as fibrin glue can stabilize the granules in the implantation site and produce a composite that can be moulded into the defect without empty spaces [3].

Many processing routes have been used for fabrication of porous hydroxyapatite granules, such as hydrothermal conversion of natural corals [4], crushing of sintered blocks, granulation by vibration and rolling [5], dripping procedure, casting in plaster mould, emulsion methods [6], spray-drying process. However, these processes do not yield granules with optimal properties for medical applications. A last method similar to the lost wax process consists in building a calcium carbonate scaffold around a model part constituted of piled up calibrated PMMA balls. After thermal treatment, the ball debinding resulting empty space is filled by HA powder aqueous slurry. After carbonate scaffold elimination, controlled size and shape HA beads are obtained [7].

Besides their use as bone filling material, these HA beads if presenting any microporosity could be used in the orthopedic field as drug delivery carriers, such as growth factors, anticancer drugs, antibiotic agents. . . Among these products, the gentamicin antibiotic is frequently used for its prophylactic action. Another type of substances like phages used for phagotherapy in case of nosocomial diseases can also be incorporated in porous beads.
In this study, we present the fabrication process for dense, micro and macro-porous HA beads from lost wax process and comparative results of drug loading and release rate in the microporous HA beads with gentamicin antibiotic and lambda phage

\section{EXPERIMENTAL}

\section{HA powder synthesis}

HA powder was prepared by aqueous precipitation technique using a diammonium phosphate solution and a calcium nitrate solution. Details of the procedure have been published elsewhere [8]. After successive steps of precipitation-calcination-milling, the as-obtained powder presents a surface area of $5 \mathrm{~m} 2 / \mathrm{g}$, mean particle size of $1 \mu \mathrm{m}, \mathrm{Ca} / \mathrm{P}$ ratio of 1.66 , high purity verified by transparency of hot isostatic pressed samples. A complete densification is achieved by pressureless sintering after 3 hours at $1250{ }^{\circ} \mathrm{C}[8]$.

\section{Fabrication of ceramic beads}

The porous ceramic beads are fabricated through the lost wax process. The first step is to elaborate a model part in organic balls, to infiltrate it by calcium carbonate slurry and to burn the organic species by thermal treatment. The as-resulting voids are filled with HA powder slurry and the carbonate surrounding carapace is destroyed by higher thermal treatment.

\section{a) Preparation of the organic skeleton}

An organic skeleton is built by stacking PMMA balls (Diakon TM Ineos Acrylics Holland, Saluc Belgium) with diameters in the range of 100 micrometres to 3 millimetres. The bridging between polymeric balls is obtained by a 


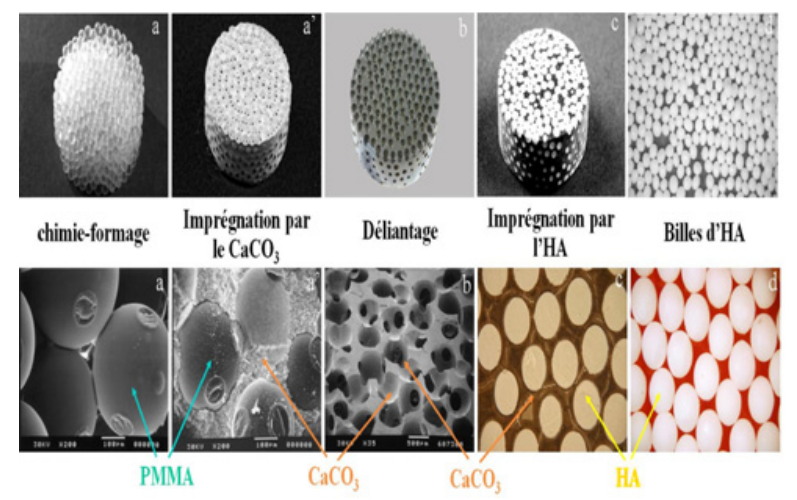

Figure 1. HA spherical granules elaboration procedure.

chemical treatment using acetone (RPE 99.8\% Carlo Erba, France) which exhibits a dissolution chemical action with respect to the PMMA and induces an overlapping between the individual bodies (Fig. 1a).

\section{b) Preparation of calcium carbonate scaffold}

The as-prepared organic skeleton is then impregnated by the calcium carbonate suspension in order to fill voids between polymeric PMMA balls. $\mathrm{CaCO} 3$ powder (Mikhart 2, Provençale s.a, France) presents a surface area of $3.3 \mathrm{~m} 2 / \mathrm{g}$, mean particle size of $3 \mu \mathrm{m}$ and a purity level superior to $99 \%$.

$\mathrm{CaCO} 3$ aqueous slurry was prepared with $64 \mathrm{wt} \%$ dry matter. Slurry defloculation is assured by Darvan C ( R.t.Vanderbilt.Co) in amount equal to $1.5 \mathrm{wt}$. \% of $\mathrm{CaCO} 3$ content. A quantity of organic binder (4 wt. \% of $\mathrm{CaCO} 3$ content, Duramax B1001, Rohm and Haas) was added to ensure a consolidation of green material during the debinding treatment. Slip preparation is carried out using a planetary ball mill with agate container and balls. Milling duration is fixed to 1 hour with a rotation speed equal to 180 revolutions per minute. After infiltration process (Fig 1a'), the sample is dried in a plaster mould and debound by heating to $220^{\circ} \mathrm{C}$ during 20 hours followed by a dwell at $250^{\circ} \mathrm{C}$ for 10 hours. The elimination of PMMA balls creates a controlled size macroporosity within the ceramic. After debinding, the $3 \%$ residual organic ensures a sufficient mechanical strength for the handling of samples during the later stages and the sample is constituted of macropores with a size equal to the size of the used PMMA balls. These cavities are interconnected. Figures 1a' represent a macroscopic and microscopic views of $\mathrm{CaCO} 3$ impregnated organic skeleton. The calcium carbonate scaffold after debinding is presented in Fig. 1b.

\section{c) Manufacturing of dense or microporous HA beads}

HA aqueous slurry was prepared under the same experimental conditions than $\mathrm{CaCO} 3$ suspension. Powder concentration was equal to $75 \mathrm{wt}$. \% and dispersion powder was assured by Darvan C in amount equal to $1.5 \mathrm{wt} . \%$ of HA content.

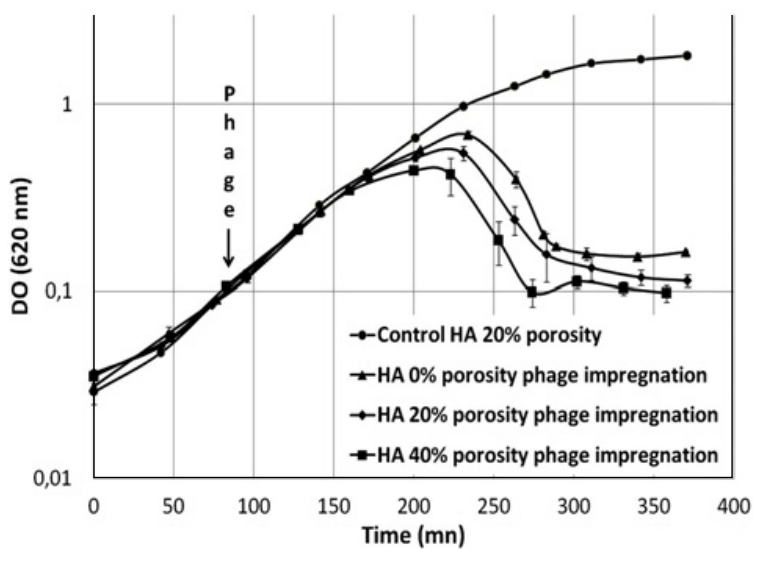

Figure 2. Bacterial growth kinetics measured by optical density at $620 \mathrm{~nm}$ in presence of various porosity ceramic phage supports.

Calcium carbonate scaffold is impregnated by aqueous suspensions of hydroxyapatite in order to fill cavities left by the PMMA balls. This operation is performed into a plaster mould in order to allow the drying of the part.

Figure 1c represents a macroscopic view of polished $\mathrm{CaCO} 3$ scaffold filled with hydroxyapatite after drying. After filling $\mathrm{CaCO} 3$ scaffold by the hydroxyapatite powder, the material is heated up to $1000^{\circ} \mathrm{C}$ to transform the calcium carbonate to lime and to induce a pre-sintering of HA powder and a consolidation of the ceramic balls in order to resist during the demolition of calcium carbonate scaffold.

During cooling, the samples undergo a water quenching from $200{ }^{\circ} \mathrm{C}$ to transform lime into calcium hydroxide. This reaction is accompanied by a significant swelling of the structure causing the $\mathrm{CaCO} 3$ ceramic disintegration and the HA beads releasing. After this step, HA balls and $\mathrm{Ca}(\mathrm{OH}) 2$ powder are separated by mechanical sieving.

Figures 1d represent a macroscopic view of HA beads obtained using $\mathrm{CaCO} 3$ scaffold made from various PMMA balls diameters in the range of 100 micrometres to 3 millimetres calibrated balls.

In order to obtain different porosity ranges, beads are sintered at different temperatures: 1275,1150 and $1100{ }^{\circ} \mathrm{C}$. Sintering at the highest temperature makes it possible to obtain $97.5 \%$ as relative density. On contrary, the lowest temperatures $\left(1150\right.$ and $\left.1100^{\circ} \mathrm{C}\right)$ offer porous beads characterized by an micronic open porosity volume equal to 20 and $42 \%$ respectively.

\section{BIOLOGICAL FUNCTIONALIZATION}

Bacterial strain, phage, media and growth conditions.

The bacterium used in this study is Escherichia coli K12 strain (A324). This bacterium is lytic $\lambda$ phage sensitive. The bacterium was grown at $150 \mathrm{rpm}$ and incubated at $37^{\circ} \mathrm{C}$, in agitation $170 \mathrm{rpm}$ in Luria-Bertani broth (LB: bactotrypton at $5 \mathrm{~g} / \mathrm{l}$, yeast extracts at $10 \mathrm{~g} / \mathrm{L}$, $\mathrm{NaCl}$ at $5 \mathrm{~g} / \mathrm{l}$ and $\mathrm{pH}$ 7.2). Solid media used is the Rmedium (added agar at $15 \mathrm{~g} / \mathrm{L}$ ).

Phage $\lambda$ vir used as antibacterial loading agents is a lytic phage and conserves all virulence properties. 
The $\lambda$ vir stock was prepared by infecting Escherichia coli K12 strain (A324). All the HA samples corresponding to different sintering conditions were incubated for $24 \mathrm{~h}$ with $5 \mathrm{ml}$ of stock $\lambda$ phage. After incubation, the sample was washed once with LB medium to remove excess phage suspension.

Cultures of $30 \mathrm{ml}$ of Escherichia coli K12 (A324) in LB liquid medium were performed for each condition. The growth of E. coli was performed at $37^{\circ} \mathrm{C}$ with agitation at $170 \mathrm{rpm}$. To measure bacterial growth, optical density of about 0,12 at $620 \mathrm{~nm}$ was followed. The $\lambda$ phageloaded HA samples were introduced into culture tubes after obtaining a growth of two generations. Growth was followed until complete lysis of bacteria.

\section{RESULTS AND DISCUSSION}

Figure 2 shows the efficiency of bacterial lysis $\lambda$ phageloaded HA samples according to their microporosity (depending on sintering temperature). As shown on the graph, the phage impregnated ceramic parts are introduced in the bacterial medium after about 90 minutes (after development of 2 bacterial generations). We can notice that the lyse of bacteria takes place after about 90 minutes all the more quickly as the microporosity of the ceramic is high. For all samples, a total bacterial destruction is noticed after 1 more hour. It is interesting to note that the dense HA sample (sintered at $1275^{\circ} \mathrm{C}$ ) presents also an antibacterial effect which indicates a strong interaction between bacteriophage lambda with the HA ceramic surface.

\section{CONCLUSIONS}

These first experiments reveal that microporous HA microspheres can be used as a matrix for local drug delivery system to prevent and curate infections associated to bone implants. The drug release quantity and duration can be controlled by the morphology and microstructure of HA beads and in particular by the porous volume in order to obtain drug delivery system according with the therapeutic dosage.

\section{References}

[1] Burg, K.J.L., Porter, S., Kellam, J.F., Biomaterial developments for bone tissue engineering. Biomaterials., 21. (2000) 2347-2359.

[2] Daculsi, G., LeGeros, R.Z., M. Heughebaert, M., Barbieux, I., Formation of carbonate-apatite crystals after implantation of calcium phosphate ceramics. Calcif Tissue Int., 46, (1990) 20-27.

[3] Le Nihouannen, D., Le Guehennec, L., Rouillon, T., Pilet, P., Melitta Bilban, M., Layrolle, P., Daculsi, G., Micro-architecture of calcium phosphate granules and fibrin glue composites for bone tissue engineering. Biomaterials., 27, (2006) 2716-2722.

[4] Roy, D.M., Linnehan, S.K., Hydoxyapatite formed from coral skeletal carbonate by hydrothermal exchange. Nature., 247, (1974) 220-222.

[5] Zhang, X., Chen, J., Zhou., Porous hydroxyapatite granules: their synthesis, applications and characterization. Clin Mater.,4, (1989), 319-327.

[6] Lee, J.S., Park, J.K., Processing of porous ceramic spheres by pseudo-double-emulsion method. Ceramics International., 29, (2003), 271-278.

[7] M Descamps, J.C Hornez, A Leriche. Manufacture of hydroxyapatite beads for medical applications. Journal of the European Ceramic Society, 29(3), (2009), 369375.

[8] J.C Hornez, F Chai, F. Monchau, N Blanchemain, M Descamps, H.F. Hildebrand. Biological and physicochemical assessment of hydroxyapatite (HA) with different porosity, Biomolecular Engineering, 24, (2007) 505-09. 